\title{
Induction of sperm maturation in vitro in epididymal cell cultures of the tammar wallaby (Macropus eugenii): disruption of motility initiation and sperm morphogenesis by inhibition of actin polymerization
}

\author{
M. Lin'1,3, R. Hess ${ }^{4}$ and R. J. Aitken 1,2 \\ ${ }^{1}$ Cooperative Research Centre for Conservation and Management of Marsupials, \\ Discipline of Biological Sciences and ${ }^{2}$ Hunter Medical Research Institute, The University \\ of Newcastle, NSW 2308, Australia; 3Jiangxi Provincial Key Laboratory for Animal \\ Biotechnology, Jiangxi Agricultural University, Nanchang, Jiangxi, 330045, \\ People's Republic of China; and ${ }^{4}$ Department of Veterinary Biosciences, \\ University of Illinois, 2001 S. Lincoln, Urbana, IL 61802, USA
}

A sperm-epididymal cell co-culture was shown to be capable of inducing the in vitro maturation of spermatozoa from a marsupial species, the tammar wallaby (Macropus eugenii). This system was able to maintain wallaby epididymal epithelial cells in vitro for more than 2 months. The system also enabled immature wallaby spermatozoa to differentiate from a T-shaped to a streamlined form, accompanied by the development of progressive motility after co-culture with epididymal cell monolayers that had been cultured for 7 days. The addition of inhibitors of actin polymerization (latrunculin A or B) to the co-culture system showed that wallaby sperm maturation was impaired by the interruption of actin organization within the immature spermatozoa. These results indicate that actin filaments play a significant role in sperm transformation during post-testicular maturation in marsupials. These observations also indicate that the marsupial coculture system has the potential to greatly increase understanding of sperm-epididymal cell interactions and the mechanism of sperm maturation in these species.

\section{Introduction}

The development of in vitro systems of reproductive tract cell cultures for studying post-testicular sperm maturation in eutherian mammals has progressed markedly during the past two decades. In the eutherian systems, epididymal epithelial cells can be grown in culture, form confluent monolayers, retain their structural features and junctional relationships, and maintain their polarity and pinocytotic activity (Moore et al., 1986, 1992; Cooper et al., 1990; Byers et al., 1992). In culture, these cells can also metabolize testosterone to the active metabolite, dihydrotestosterone (Raczek et al., 1994; Carballada and Saling, 1997), and secrete several specific protein products from different sections of the epididymis, such as $\mathrm{N}$-acetylglucosaminidase (Yeung et al., 1989; Cooper et al., 1990). More significantly, epididymal epithelial cultures have been used for co-incubation with immature spermatozoa recovered from testes or the caput epididymidis, and such co-culture systems have established that spermatozoa can undergo maturation in vitro, including acquisition of progressive motility and fertilizing capacity (Moore et al., 1986, 1992; Moore and Akhondi, 1996). An epididymal epithelial-sperm co-culture system for marsupial species has been developed, which enables immature spermatozoa

Email: biml@alinga.newcastle.edu.au of the brushtail possum (Trichosurus vulpecula) to differentiate morphologically and develop progressive motility (Lin et al., 2000).

Epididymal maturation in marsupials, as in eutherians, is critical for spermatozoa to acquire a capacity for fertilization (Setchell, 1970; Harding et al., 1979; Jones et al., 1984; Jones and Clulow, 1994; Temple-Smith, 1994; Jones and Murdoch, 1996; Rodger, 1997; Lin et al., 2000). However, the marsupial pattern of epididymal maturation involves a greater range of structural changes than that seen in eutherians. In many groups of Australian marsupials, some sperm organelles do not complete their formation by the time they have emerged from the testes, and extensive morphological modifications and structural reorganization during epididymal transit are required to complete these changes (Cummins, 1976; Temple-Smith and Bedford, 1976; Harding et al., 1976, 1979, 1983, 1984; Mate and Rodger, 1996; Setiadi et al., 1997; Lin and Rodger, 1999). For example, on leaving the testis, spermatozoa of the tammar wallaby (Macropus eugenii) and brushtail possum (Trichosurus vulpecula) have an elongated 'scoop'-shaped acrosome with front and lateral projections protruding away from the nucleus. The immature acrosome condenses into its mature form as a compact button-like organelle as spermatozoa pass down the epididymal duct and reach the cauda epididymidis (Lin et al., 1997; Lin and Rodger, 1999). In addition to the 
structural changes at the subcellular level, the head orientation of spermatozoa in some marsupial species is changed from perpendicular to the mid-piece (T-shaped) when they enter the caput epididymidis, to parallel to the longitudinal axis of the spermatozoa (streamlined-shaped) as they reach the distal cauda epididymidis (Temple-Smith and Bedford, 1976; Bedford, 1991; Setiadi et al., 1997; Lin and Rodger, 1999). Thus, marsupial spermatozoa display complex and extraordinary morphological changes and structural reorganization in the epididymis. This phenomenon is unique to marsupials and indicates that these species may be excellent models for studies of sperm maturation and epididymal function using in vitro systems, as they have such an extreme and readily visible morphological maturation process.

Actin has been detected in the testis and spermatozoa of several mammals including mice, rabbits, dogs, boars (see Castellani-Ceresa et al., 1992) and humans (Liu et al., 1999). An immunocytochemical study of tammar wallaby spermatozoa revealed that the distribution of actin filaments (F-actin) is temporally and spatially associated with the process of acrosomal maturation in the epididymis (Scarlett et al., 2000). In tammar wallabies, F-actin is not detected in the acrosome of testicular spermatozoa, but is deleted in the folding acrosome of caput and corpus epididymal spermatozoa. As the spermatozoa complete their acrosomal morphogenesis in the cauda epididymidis, F-actin is no longer visible in the acrosome. This finding indicates that F-actin stabilizes the position and shape of the acrosome during both spermiogenesis and post-testicular sperm maturation. Actin filaments may play a significant role in the acrosomal transformation, as they are often involved in morphological changes in somatic cells.

This paper describes an in vitro cell culture system for tammar wallaby spermatozoa, which is able to support sperm maturation induced by cultured epididymal epithelial cells. Addition of latrunculins A and B to disrupt sperm actin polymerization in the in vitro co-culture system was used to investigate whether post-testicular sperm morphogenesis depends on actin filament assembly within the spermatozoon.

\section{Materials and Methods}

\section{Animals}

Five adult male tammar wallabies (Macropus eugenii) were obtained from the captive breeding colony established from animals caught on Kangaroo Island, South Australia, and bred in the holding yard of the Animal Services Unit at The University of Newcastle, New South Wales, Australia. The use of protected animals and animal experimentation were approved by the appropriate State authorities and by the Animal Care and Ethics Committee of The University of Newcastle.

\section{Tissue and cell culture preparation}

The epididymal cell culture system for the tammar wallaby was established for the procedure used for the brushtail possum in a previous study (Lin et al., 2000). In brief, epididymal tubule fragments were obtained from the caput, corpus and cauda epididymides after animals were killed with an overdose of sodium pentobarbitone (at least $30 \mathrm{mg} \mathrm{kg}{ }^{-1}$ body weight; Virbac, Peakhurst) via a lateral tail vein. Loops of tubules from each epididymal segment were covered with an epididymal cell culture medium (see below) and minced into fragments (1-2 $\mathrm{mm}$ in length). The tubule fragments were transferred into fresh culture medium containing 0.05\% (w/v) collagenase (type XI; Sigma, St Louis, $\mathrm{MO})$, and incubated for $6 \mathrm{~h}$ at $37^{\circ} \mathrm{C}$ in $5 \% \mathrm{CO}_{2}$ in air. After incubation, tubule fragments were washed by six changes of the culture medium to remove collagenase and debris. Approximately 30-50 washed tubule fragments in $1 \mathrm{ml}$ fresh culture medium were transferred to each well of a Falcon 24-well flat bottom tissue culture plate (Becton Dickinson Labware, Lincoln Park, NJ). The cultures were incubated at $37^{\circ} \mathrm{C}$ in $5 \% \mathrm{CO}_{2}$ in air with humidity at $100 \%$ in a laboratory incubator (Heraeus Instruments, Hanau). Cell culture samples prepared for electron microscopy were treated in the same manner as described above, except that the tubule fragments in $1 \mathrm{ml}$ fresh medium were transferred to a Falcon cell culture insert $(25 \mathrm{~mm}$ in diameter, six-well format, $0.4 \mu \mathrm{m}$ pore size on PET track-etched membrane; Becton Dickinson Labware Europe, Meylan Cedex). The inserts were then placed in the well of a Falcon Multiwell cell culture insert plate (Becton Dickinson Labware, Franklin Lakes, NJ) containing $1 \mathrm{ml}$ fresh medium. For control samples, cell cultures of wallaby small intestine cells were established using the same procedure as described for epididymal cells. All cultures were maintained by changing the medium once per day.

\section{Culture medium preparation}

The medium used for the wallaby epididymal cell cultures was the same as that used for possum epididymal cell culture media (Lin et al., 2000). One hundred millilitres of medium consisted of 90 ml RPMI 1640 (Sigma-Aldrich, Irvine) and $10 \mathrm{ml}$ fetal calf serum (Biosciences, Castle Hill, NSW) supplemented with $11.0 \mathrm{mg}\left(1 \mathrm{mmol} \mathrm{I}^{-1}\right)$ D-sodium pyruvate (Sigma-Aldrich), $0.058 \mathrm{mg}\left(100 \mathrm{nmol} \mathrm{I}^{-1}\right)$ insulin (Sigma-Aldrich, Steinheim), $7.2 \mu \mathrm{g}$ (200 nmol $\mathrm{I}^{-1}$ ) hydrocortisone (Sigma), $39.5 \mu \mathrm{g}\left(200 \mathrm{nmol} \mathrm{I}^{-1}\right)$ testosterone (Sigma), $29.0 \mu \mathrm{g}\left(1 \mu \mathrm{mol} \mathrm{\textrm {I } ^ { - 1 }}\right)$ dihydrotestosterone (Sigma), $500 \mu \mathrm{g}$ transferrin (Sigma), $100 \mu \mathrm{g}$ retinol acetate (Sigma) and $5000 \mathrm{iu}$ penicillin and $5 \mathrm{mg}$ streptomycin (Trace Scientific, Noble Park, Victoria). The medium was filtered with a $0.20 \mu \mathrm{m}$ Minisart filter (Sartorius, Göttingen) and stored at $4^{\circ} \mathrm{C}$.

\section{Co-culture of epididymal epithelial cells and spermatozoa}

Immature spermatozoa used for investigation of sperm maturation in vitro were obtained from the proximal caput region of the epididymis. Dissected epididymal proximal caput regions were minced into small pieces and covered 
with $1 \mathrm{ml}$ fresh culture medium. The culture dish was then placed in an incubator for $1 \mathrm{~h}$ at $37^{\circ} \mathrm{C}$ in $5 \% \mathrm{CO}_{2}$ in air, and agitated occasionally to facilitate the diffusion of spermatozoa from the tubules. After incubation, the medium containing free spermatozoa was recovered carefully by aspiration and diluted to a final concentration of approximately $13 \times 10^{6}$ spermatozoa $\mathrm{ml}^{-1}$. An aliquot $(0.2 \mathrm{ml})$ was added to 7-day-old cell cultures of caput epididymal cells in $1 \mathrm{ml}$ medium. The final concentration of spermatozoa in the preparations was approximately $2.2 \times 10^{6} \mathrm{ml}^{-1}$. The coculture preparations were incubated at $37^{\circ} \mathrm{C}$ in $5 \% \mathrm{CO}_{2}$ in air with $100 \%$ humidity, and maintained by changing the medium once per day. For experimental controls, the same number of spermatozoa was added to $1 \mathrm{ml}$ culture medium alone, or a 7-day-old small intestine epithelial cell culture in $1 \mathrm{ml}$ medium. Both controls were incubated under the same conditions as the epididymal cell cultures.

\section{Assessment of sperm maturation in vitro}

Changes in sperm head orientation and development of sperm motility were examined as indicators of sperm maturation in the co-culture preparations. Spermatozoa in $100 \mu \mathrm{l}$ medium from different epididymal cell co-cultures were transferred to a HybriWell Chamber (Astral Scientific, Gymea, NSW) on a glass slide and examined in a Zeiss microscopic incubator at $37^{\circ} \mathrm{C}$ in $5 \% \mathrm{CO}_{2}$ in air with $100 \%$ humidity to observe changes in sperm head orientation. The percentages of spermatozoa with changed head orientation were calculated from groups of approximately 300 spermatozoa in each co-culture. Means and standard deviations were obtained for Student's $t$ test after square root transformation.

Sperm motility was assessed each day by examining video recordings of spermatozoa cultured in a Zeiss microscopic incubator (at $37^{\circ} \mathrm{C}$ in $5 \% \mathrm{CO}_{2}$ in air with $100 \%$ humidity) on an Axiovert S100 inverted microscope (Carl Zeiss, Oberkochen).

\section{Immunofluorescence}

Cytokeratin was used as a marker for identification of epididymal epithelial cells in this study as filaments of an intermediate size containing cytokeratin are characteristic of epithelial cells and are restricted to cells of epithelial origin (Franke et al., 1978; Sun et al., 1979; Olson et al., 1983). A mouse monoclonal anti-pan cytokeratin conjugate FITC (Sigma-Aldrich), which exhibited a wide range of interspecies crossreactivity including marsupials, rat kangaroos and brushtail possums (Lin et al., 2000), was used to label cultured wallaby epididymal epithelial cells. In brief, cultured cells in 24-well culture plates were rinsed

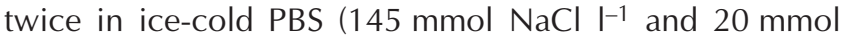
sodium phosphate $\mathrm{I}^{-1}, \mathrm{pH} 7.4$ ), and then permeabilized on ice for $15 \mathrm{~min}$ in $0.1 \%(\mathrm{v} / \mathrm{v})$ Triton X-100 in PBS. After rinsing twice in cold PBS, the cells were fixed for $5 \mathrm{~min}$ in ice-cold absolute methanol. After fixation, the cells were rinsed three times for $5 \mathrm{~min}$ each in $1 \%(\mathrm{w} / \mathrm{v})$ BSA in PBS, and incubated with $1 \%$ BSA in PBS in a humid chamber for $1 \mathrm{~h}$ at room temperature. After blocking, the cells were incubated in a 1:10 dilution of the monoclonal anticytokeratin antibody conjugate FITC for $2 \mathrm{~h}$ at $36^{\circ} \mathrm{C}$. After three washes for 5 min each in PBS with $1 \%$ BSA, the cells on the bottom of wells were covered with a solution of nine parts glycerol to one part PBS $(\mathrm{pH}$ 7.8) for evaluation under a fluorescence microscope.

\section{Light microscopy}

Living cells in the culture plates were photographed on successive days of culture with a Carl Zeiss MC 200 Chip Microscope camera on a Zeiss Axiovert S100 inverted phase-contrast microscope. Fluorescent micrographs were taken through a Zeiss No. 9 (FITC) filter system with blue excitation of $450-490 \mathrm{~nm}$.

\section{Electron microscopy}

Cells grown on membranes of Falcon cell culture inserts were fixed with $3 \%(\mathrm{v} / \mathrm{v})$ glutaraldehyde in $0.14 \mathrm{~mol} \mathrm{PBS} \mathrm{I}^{-1}$, $\mathrm{pH} 7.4$, at $4^{\circ} \mathrm{C}$ overnight. The cells were rinsed in PBS, postfixed in $0.1 \%(\mathrm{w} / \mathrm{v}) \mathrm{OsO}_{4}$ in $\mathrm{PBS}$ for $1 \mathrm{~h}$, rinsed in PBS, dehydrated through an acetone series, and embedded in Spurr's resin (Agar Scientific Ltd, Stansted). Sections (70-100 nm) were cut on an Ultracut E ultramicrotome (Reichert-Jung, Hemalser Haupster) with a diamond knife (Diatome Ltd, Bienne), and then stained with 1\% (w/v) uranyl acetate in 30\% ethanol for 5-10 min, followed by lead citrate (Reynolds, 1963) for 5-10 min. Transmission electron micrographs (TEM) were taken using a JEOL-100CX electron microscope (JEOL, Tokyo) operating at $80 \mathrm{kV}$.

\section{Treatments of latrunculin $A$ and $B$}

Stock solutions of latrunculin A and B (Sigma) were prepared separately in dimethyl sulphoxide (DMSO) at $2 \mathrm{mg} \mathrm{ml}^{-1}$ and stored at $4^{\circ} \mathrm{C}$. Drugs were added to the culture medium (see above) at a final concentration of $2 \mu \mathrm{g}$ latrunculin $\mathrm{A}$ or $\mathrm{B} \mathrm{ml} \mathrm{ml}^{-1}$. The same volume of $\mathrm{DMSO}$ without drugs was added to the culture medium for a control.

Immature spermatozoa used for the investigation of latrunculin effects on sperm maturation in vitro were obtained from the proximal caput region of the epididymides of three tammar wallabies. The procedure used to obtain immature spermatozoa from the caput epididymidis was the same as that described above, except that the medium used to free the spermatozoa from the epididymis contained either latrunculin A or latrunculin B. These treated spermatozoa were co-cultured with 7-day-old cell cultures of caput epididymal cells in $1 \mathrm{ml}$ latrunculin A or latrunculin $\mathrm{B}$ medium at $37^{\circ} \mathrm{C}$ in $5 \% \mathrm{CO}_{2}$ in air with $100 \%$ humidity, and were maintained by changing the medium once per day. For a control, immature spermatozoa were added to a 7-day-old cell culture of caput epididymal cells in $1 \mathrm{ml}$ medium containing DMSO alone and incubated under the same conditions as the latrunculin treatments. 


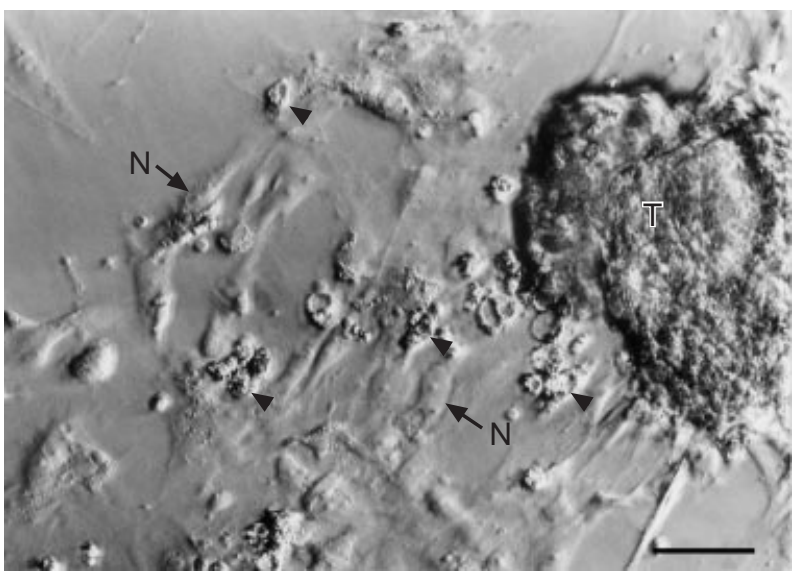

Fig. 1. Differential interference contrast micrograph of 2-day-old culture of caput epididymal cells from a tammar wallaby. As some epithelial cells are in previously established colonies on the bottom of the culture well, many other epithelial cells (arrowheads) are migrating out of an epididymal tubule fragment ( $\mathrm{T}$ ) to form monolayers on the floor of the culture well. N: nucleus of epithelial cell. Scale bar represents $20 \mu \mathrm{m}$.

\section{Results}

\section{Formation of epididymal epithelial monolayers}

After $24 \mathrm{~h}$ in culture medium, epididymal tubule fragments started to attach to the floor of the culture wells. At $48 \mathrm{~h}$, the epididymal tubule fragments in most preparations achieved firm attachment to the culture dish, and epithelial cells migrated peripherally out of the tubule plaques to form monolayers on the bottom of the culture well (Fig. 1). The migrated cells proliferated, establishing colonies of typical epididymal epithelial cells, and ultimately formed monolayers with densely packed polygonal cells (Fig. 2). The nucleus of the epithelial cells in the monolayer was oval and contained distinct nucleoli, and the cytoplasm was full of phase-dense granules (Fig. 2), consistent with the secretory and absorptive functions of these cells. As the monolayers continued to spread, new colonies of epithelial cells were established by single cells moving out of the tubule fragments and migrating across the surface of monolayers to plate on to the unoccupied floor of the culture well (Fig. 1). The epididymal tubule fragments that did not firmly attach to the floor of culture wells and individual epithelial cells shed from epididymal tubules by the digestion of collagenase did not contribute to the cell monolayers and subsequently degenerated.

In most preparations, the epididymal epithelial cells outgrew the fibroblasts and other connective cells in the culture medium. After 7 days in culture, the monolayers of the epithelial cells reached confluence and covered $80-90 \%$ of the well floor. Their epithelial characteristics were maintained in culture, as confirmed by positive immunofluorescent staining for cytokeratins in the cytoplasm (Fig. 3) and their ultrastructural appearance (Figs 4-6). The epididymal epithelial cells remained viable for $>4$ months in culture and displayed the typical epithelial

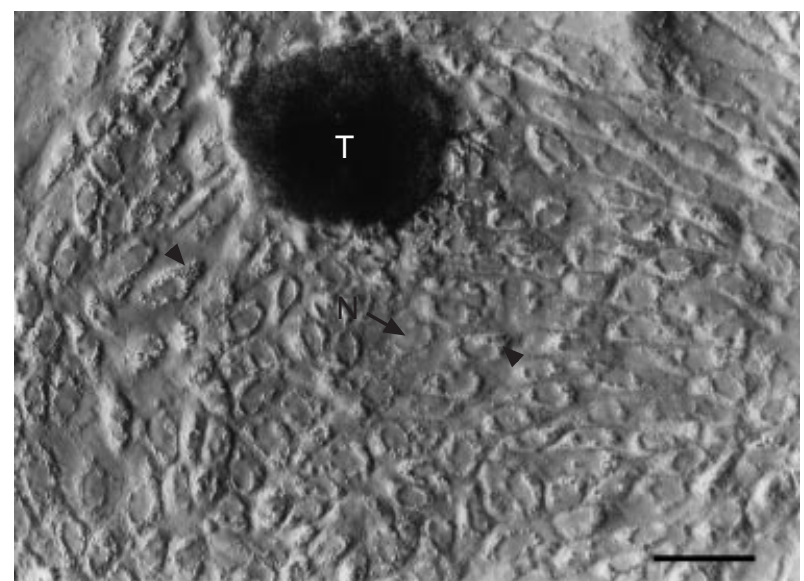

Fig. 2. Differential interference contrast micrograph of 7-day-old culture of caput epididymal cells from a tammar wallaby, showing the cultured epididymal epithelial cells forming the monolayer and covering the floor of the culture well. The caput epididymal epithelial cells are polygonal with numerous granules (arrowheads) in their cytoplasm. N: nucleus of the epithelial cell; T: caput epididymal tubule fragment. Scale bar represents $20 \mu \mathrm{m}$.

characters peculiar to the different segments of the epididymis.

Initially, as whole epididymal tubule fragments were plated, the cell cultures contained non-epithelial cells, including fibroblasts, contractile myoid cells and blood cells. However, in most cases, non-epithelial cells failed to form extensive overgrowths if epithelial cell monolayers survived in the culture. Non-epithelial cells flourished only when the epithelial cell monolayers were dissociated in the culture.

\section{Ultrastructure of cultured caput epididymal epithelial cells}

In the present study, cultured epithelial cells from the caput epididymidis were used for co-culture with immature spermatozoa. Caput epididymal epithelial cells cultured for 12 days were observed under an electron microscope to assess the ultrastructural status of the cells during the period of co-culture with immature spermatozoa. After 12 days in culture, the caput epithelial cells retained their stereocilia with distinctive slender branches (Fig. 4). The stereocilia were localized to a discrete region on the cultured cells, which normally characterizes the apical surface of the principal cells in the intact epididymis. Electron-dense secretory granules and transparent pinocytotic vesicles were scattered throughout the cytoplasm, and were concentrated particularly in the apical area where stereocilia were located (Figs 4 and 5), indicating some secretory and absorptive activity. The cultured epithelial cells also retained abundant mitochondria, well-developed rough endocytoplasmic reticulum networks and Golgi apparatus with tightly stacked lamellae (Fig. 5). Neighbouring epithelial cells displayed close contacts and formed confluent monolayers with desmosome junctions in 12-day-old cultures 

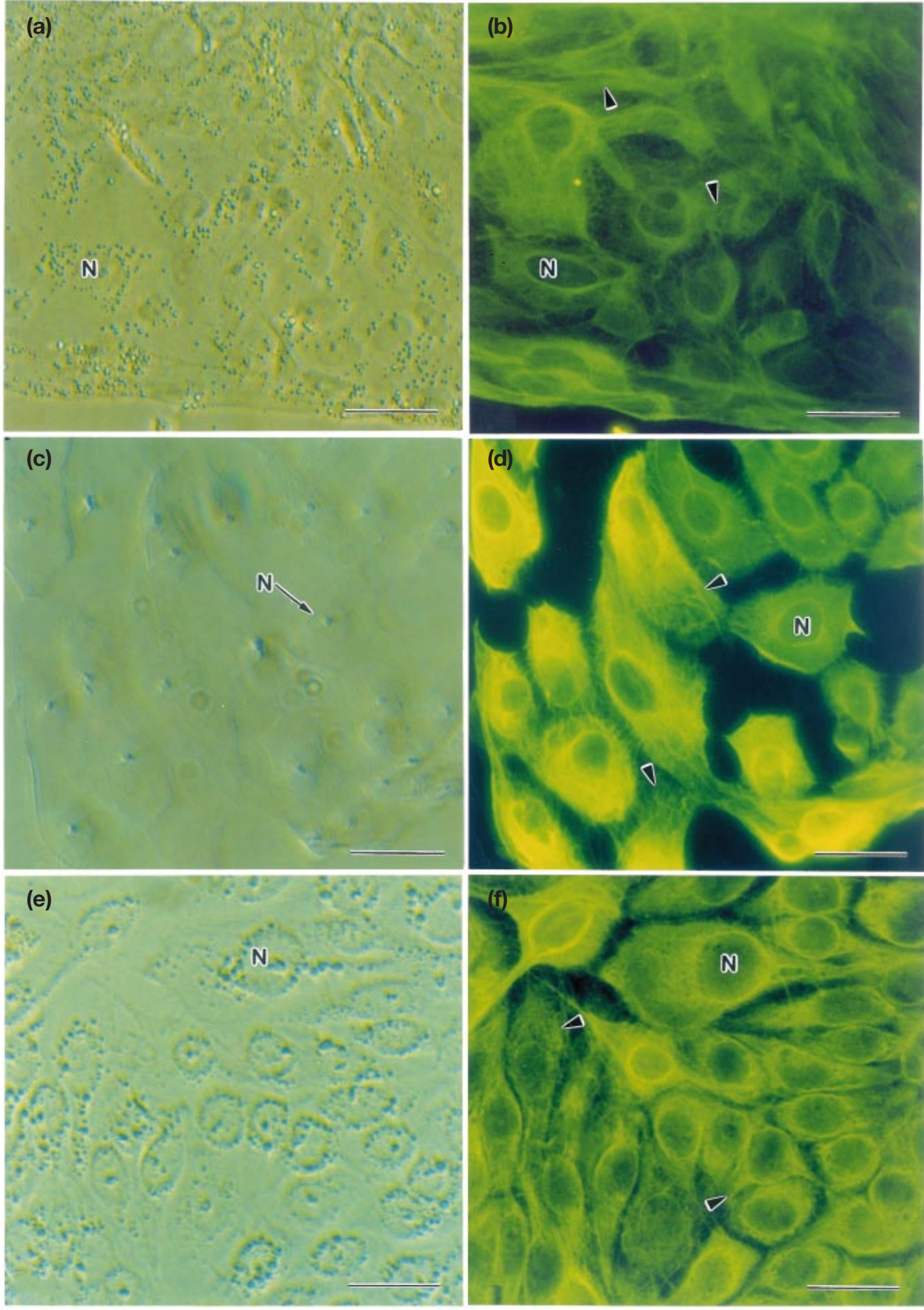

Fig. 3. (a,c,e) Differential interference contrast and $(b, d, f)$ immunofluorescent micrographs of 7-day-old culture of epididymal cells from a tammar wallaby, showing immunofluorescence of the cytokeratin network (arrowheads), a marker of epithelial cells, localized in the cytoplasm of the cultured $(a, b)$ caput, $(c, d)$ corpus and $(e, f)$ cauda epididymides. N: nucleus. Scale bars represent $10 \mu \mathrm{m}$. 


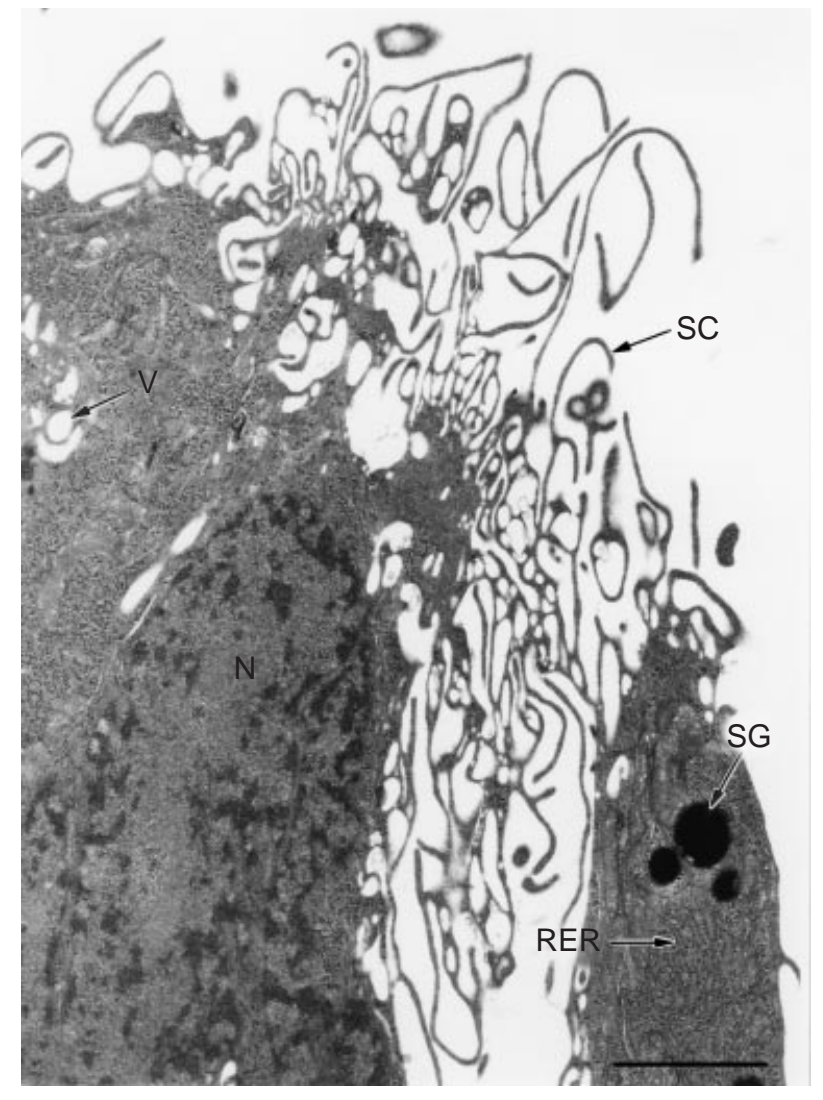

Fig. 4. Electron micrograph of apical regions of caput epididymal epithelial cells from a tammar wallaby that had been in culture for 12 days. Numerous stereocilia (SC) are located only on one side of the cell, indicating that cell polarity was maintained. Secretory granules (SG) and pinocytotic vesicles (V) appear in the cytoplasm. Rough endocytoplasmic reticulum (RER) displays normal ultrastructure. N: nucleus. Scale bar represents $2 \mu \mathrm{m}$.

(Fig. 6). In general, there was no evidence of any degenerative changes in these cultured cells.

\section{Co-culture of proximal caput epididymal spermatozoa with 7-day-old cultured caput epididymal cells}

Three experiments were conducted in an attempt to promote in vitro maturation of caput epididymal spermatozoa by $72 \mathrm{~h}$ co-culture with 7-day-old cultured tammar wallaby caput epididymal cells. Seven-day-old cultured wallaby small intestinal epithelium and culture medium alone were used as experimental controls. Immature wallaby spermatozoa recovered from the proximal region of the caput epididymidis were completely immotile and $>90 \%$ had a thumbtack or T-shaped head-mid-piece orientation. After $24 \mathrm{~h}$ in co-culture with epididymal cells, spermatozoa gradually developed motility: from twitching, slow tail beating, fast tail beating and slow to medium progressive motility. In addition to motility development, morphological maturation of spermatozoa was observed as the T-shaped spermatozoa transformed into cells with semi-

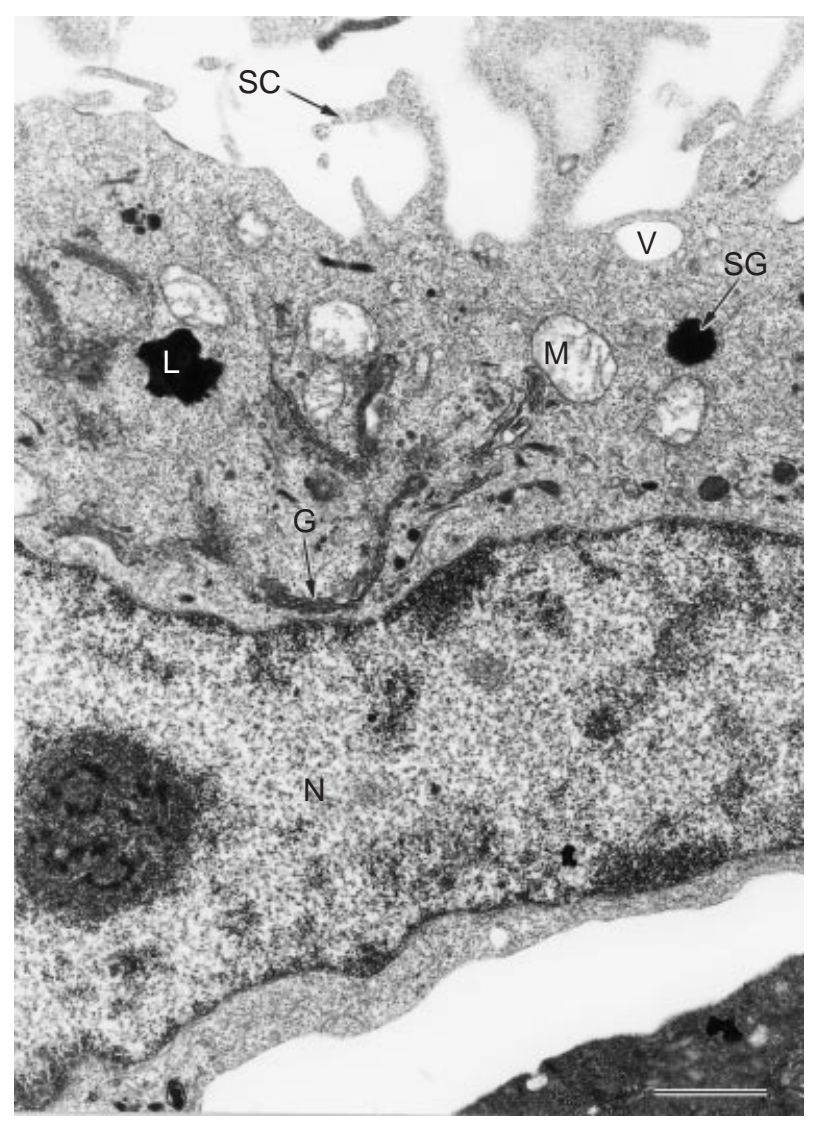

Fig. 5. Electron micrograph of a caput epididymal epithelial cell of a tammar wallaby that had been in culture for 12 days. The cell displays abundant mitochondria $(\mathrm{M})$ and well-developed Golgi apparatus (G). A few pinocytotic vesicles (V), secretory granules (SG) and lipochrome pigment deposits (L) appear in the cytoplasm close to the cell side where stereocilia (SC) are located. N: nucleus. Scale bar represents $1 \mu \mathrm{m}$.

streamlined or streamlined head-mid-piece orientation (Fig. 7). There was a significant increase in the proportion of immature spermatozoa changing from $\mathrm{T}$-shaped to streamlined head-mid-piece orientation from $24 \mathrm{~h}$ to $72 \mathrm{~h}$ in the co-culture (Figs 8 and 9). At $24 \mathrm{~h}$ of co-culture, there were fewer spermatozoa remaining in immature (T-shaped) form in the caput epididymal cell cultures compared with small intestine cell cultures $(14.98 \pm 1.71 \%$ and $33.56 \pm 3.56 \%$, respectively, $P \leqslant 0.001$; see Fig. 8 ). As the co-culture continued, the population of spermatozoa remaining T-shaped in epididymal cell cultures decreased progressively ( $5.12 \pm 1.39 \%$ at $72 \mathrm{~h}$ ). However, in the small intestine cell cultures, the T-shaped population was maintained above the $30 \%$ level for up to $72 \mathrm{~h}$ and was significantly higher $(35.48 \pm 3.53 \%$ at $72 \mathrm{~h} ; P \leqslant 0.001)$ than that in the epididymal cell cultures.

As a consequence, the proportion of mature spermatozoa with streamlined head-mid-piece orientation in caput epididymal cell cultures increased significantly from $16.99 \pm 2.05 \%$ at $24 \mathrm{~h}$ to $44.17 \pm 3.08 \%$ at $72 \mathrm{~h}$ of $\mathrm{CO}-$ culture ( $P \leqslant 0.001 ;$ Fig. 9). However, in the small intestine 


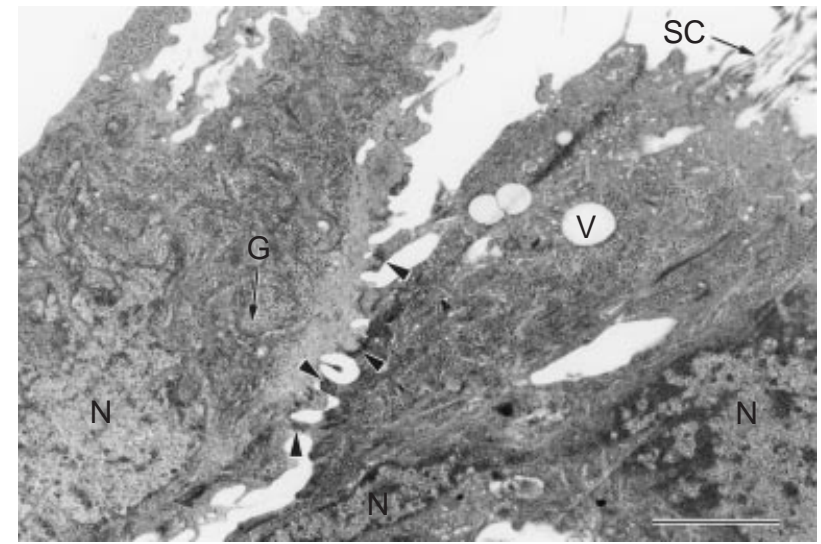

Fig. 6. Electron micrograph of tammar wallaby caput epididymal epithelial cells that have been in culture for 12 days, showing sections of two adjacent cells connected by desmosome junctions (arrowheads). The ultrastructure of stereocilia (SC), Golgi apparatus $(\mathrm{G})$ and pinocytotic vesicles $(\mathrm{V})$ are apparently sound. N: nucleus. Scale bar represents $2 \mu \mathrm{m}$.

cell cultures, there was no similar increase in the population of streamlined spermatozoa $(9.81 \pm 1.91 \%, 15.7 \pm 2.89 \%$ and $8.48 \pm 3.0 \%$ at 24,48 and $72 \mathrm{~h}$, respectively; see Fig. 9). By $96 \mathrm{~h}$, no motile spermatozoa remained in any sperm-cell co-culture. However, when dispersed in medium alone, all spermatozoa were dead by the end of $48 \mathrm{~h}$ of culture.

\section{Effects of latrunculin $A$ and $B$ on sperm maturation in caput epididymal cell culture}

Three experiments were conducted to investigate the effects of interruption of actin polymerization with latrunculin A and B on sperm maturation induced by 7 -day-old cultured tammar wallaby caput epididymal cells. The immature spermatozoa used in the experiments were obtained by releasing them from the proximal caput epididymidis into media containing either latrunculin A or B. Thus, spermatozoa had received actin inhibitor treatment before they were co-cultured with the cultured epididymal cells. After $48 \mathrm{~h}$ in co-culture, the proportion of mature (streamlined) spermatozoa was significantly lower in spermepididymal cell co-cultures containing $2 \mu \mathrm{g}$ latrunculin A or $\mathrm{B} \mathrm{ml}^{-1}(27.56 \pm 2.05 \%$ and $25.33 \pm 2.06 \%$, respectively), than in co-cultures containing DMSO only $(48.56 \pm 2.71 \%, P \leqslant 0.001$; see Fig. 10). The effects of latrunculin B were similar to those of latrunculin A, although latrunculin B was slightly less potent $(P=0.455)$. The development of sperm motility was also impaired by the treatment with either latrunculin A or latrunculin B; in the presence of these compounds, spermatozoa only displayed twitching and slow tail beating, and never showed fast tail beating and progressive motility. The latrunculin-treated spermatozoa died soon after $48 \mathrm{~h}$ in coculture, whereas vital spermatozoa were observed in the DMSO control after $72 \mathrm{~h}$.
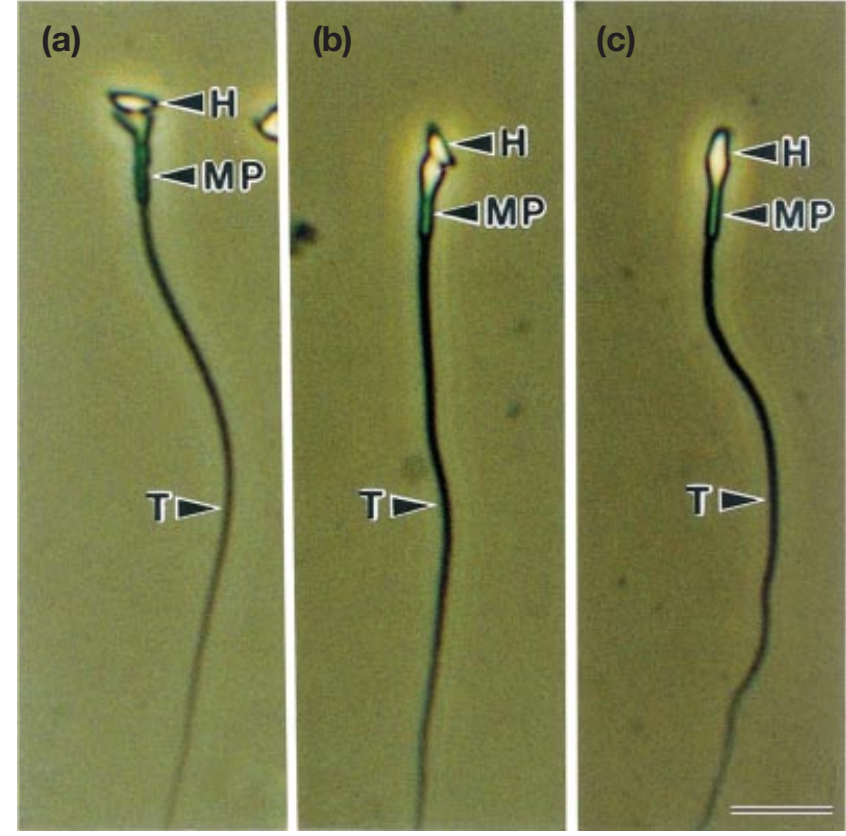

Fig. 7. Phase-contrast micrographs showing three steps of morphological maturation of wallaby spermatozoa during co-culture of immature spermatozoa and 7-day-old cultured caput epididymal cells. The sperm head-mid-piece orientation changes from (a) T-shaped (immature) to (b) about $135^{\circ}$ (semi-mature), and then to (c) streamlined (mature) forms. H: sperm head; MP: sperm midpiece; T: sperm tail. Scale bar represents $10 \mu \mathrm{m}$.

\section{Discussion}

The present study demonstrated that a sperm-epididymal cell co-culture system developed for in vitro maturation of brushtail possum spermatozoa (Lin et al., 2000) is capable of supporting the in vitro maturation of spermatozoa from another marsupial species, the tammar wallaby, which belongs to the family Macropodidae. This system was able to maintain viability of wallaby epididymal epithelial cells in vitro for more than 2 months. The system also enabled immature wallaby spermatozoa to differentiate from a T-shape to a streamlined shape, accompanied by the development of progressive motility after co-culture with epididymal cell monolayers that had been cultured for 7 days. By adding inhibitors of actin polymerization, latrunculin A and $B$, to the co-culture system, wallaby sperm maturation was shown to be impaired by interruption of actin organization in immature spermatozoa. The results of the present study indicate that actin filaments play a significant role in wallaby sperm transformation during post-testicular maturation and support the conclusion that this co-culture system will greatly increase understanding of spermepididymal cell interactions and the mechanism of sperm maturation in marsupials.

Tubule fragments from the tammar wallaby caput, corpus and cauda epididymides were used to generate epithelial monolayers in the present study. As the preparations contained both epithelial and peritubular cells that retained 


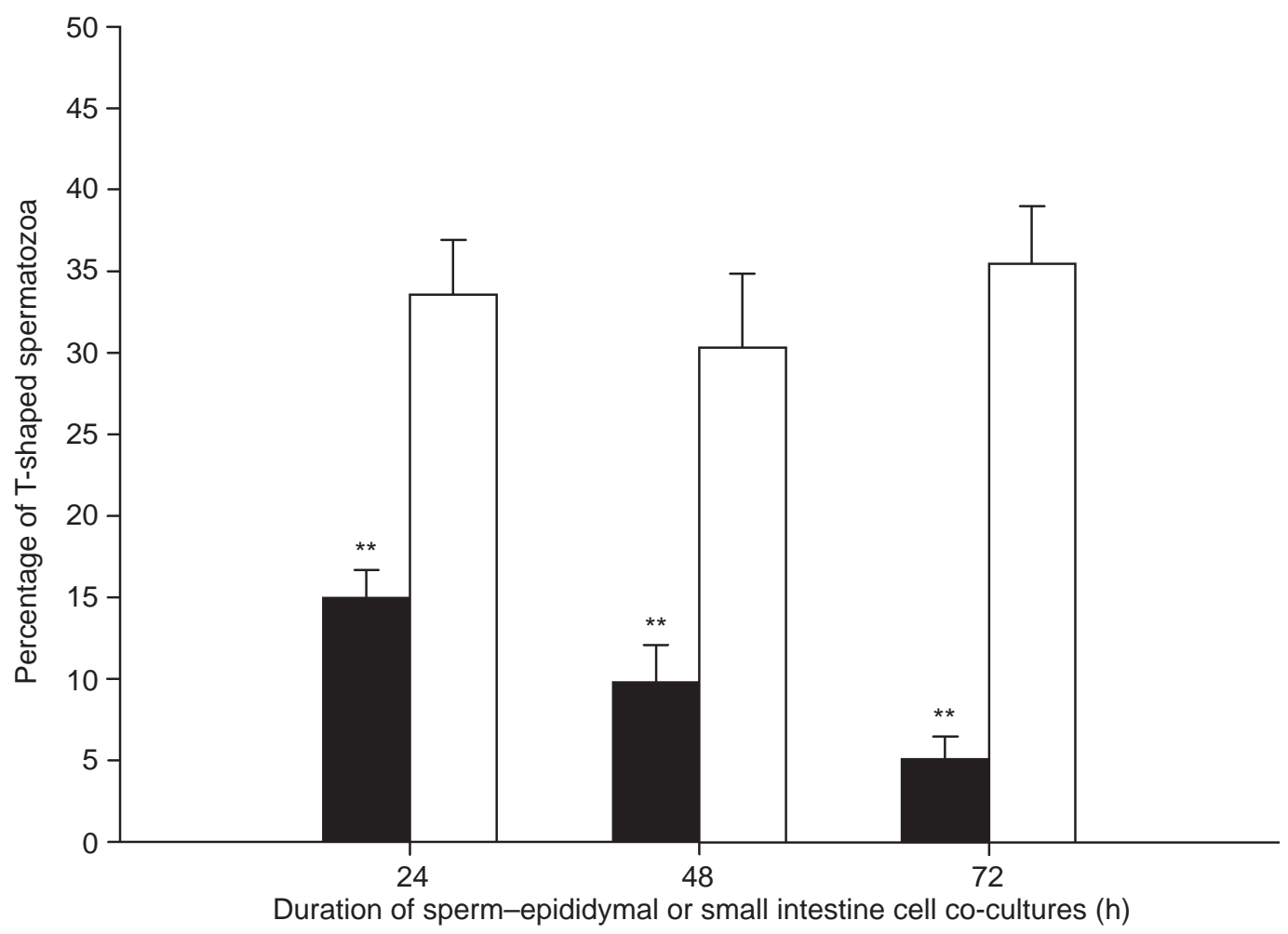

Fig. 8. Percentages of immature T-shaped tammar wallaby spermatozoa after 24,48 and $72 \mathrm{~h}$ of co-culture with monolayers of $(\mathbf{\square})$ caput epididymal and $(\square)$ small intestine cells. The population of T-shaped spermatozoa declined much more in co-cultures of epididymal cells than in cultures of small intestine cells $(* * P \leqslant 0.001)$.

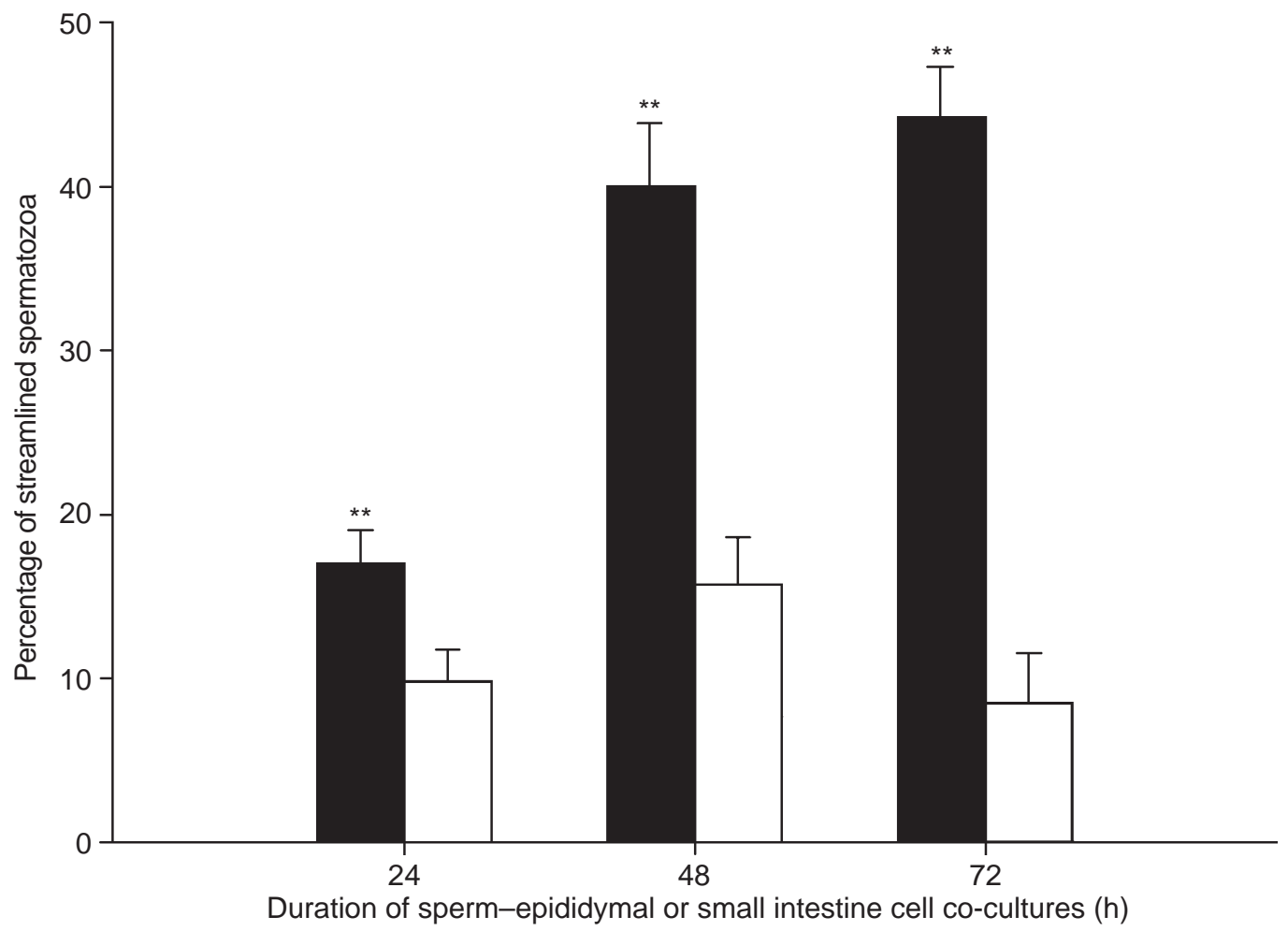

Fig. 9. Percentages of streamlined-shaped tammar wallaby spermatozoa after 24, 48 and $72 \mathrm{~h}$ of co-culture with monolayers of $(\square)$ caput epididymal and $(\square)$ small intestine cells. The population of streamlined-shaped spermatozoa was higher in co-cultures of epididymal cells than in cultures of small intestine cells $(* * P \leqslant 0.001)$. 


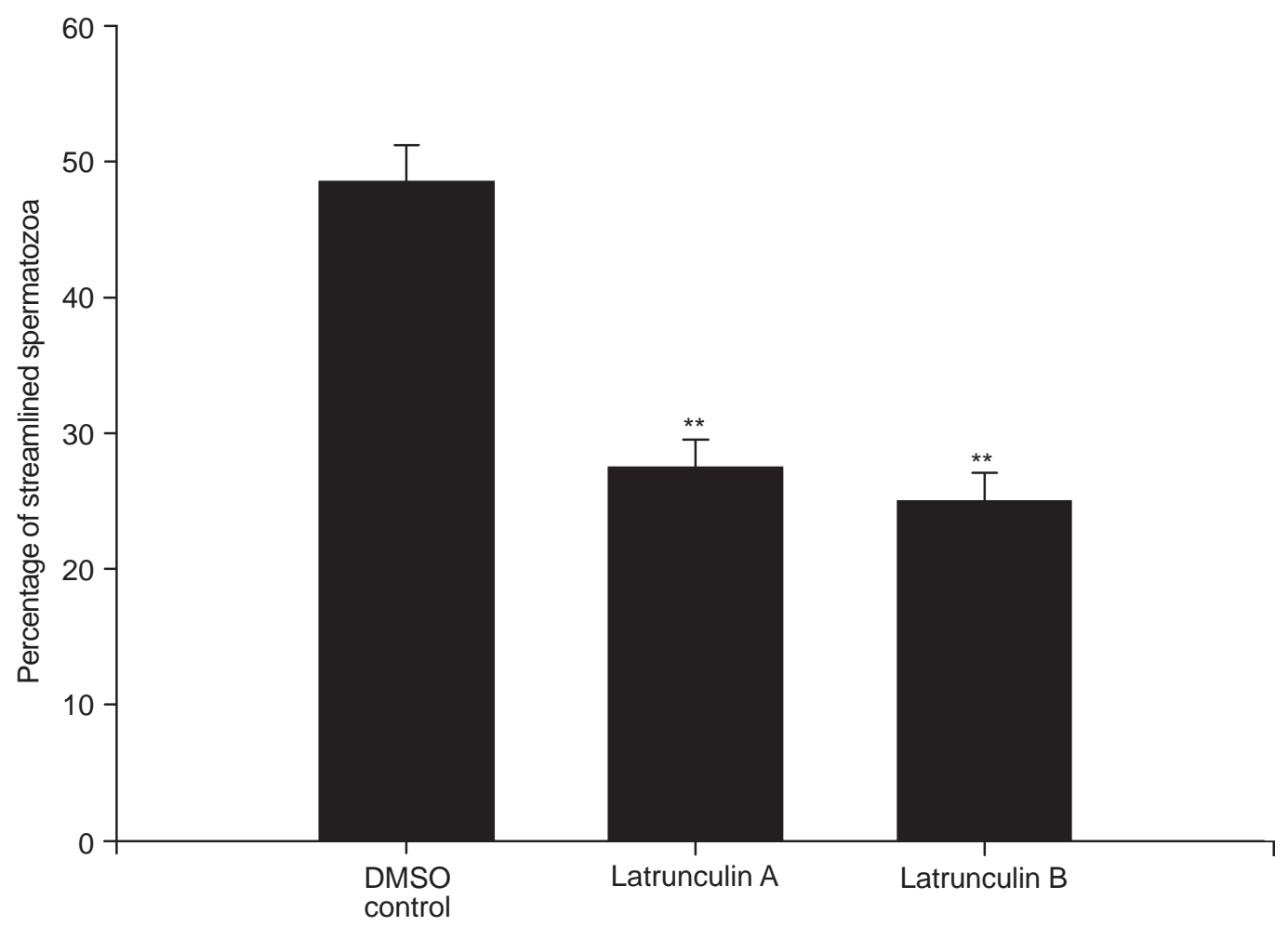

Fig. 10. Percentages of streamlined-shaped tammar wallaby spermatozoa after $48 \mathrm{~h}$ of sperm-epididymal cell co-culture in which the medium contained $2 \mu \mathrm{g} \mathrm{ml}^{-1}$ of latrunculin A, latrunculin B or dimethyl sulphoxide (DMSO) only. The population of streamlined-shaped spermatozoa was significantly lower in both latrunculin co-cultures than co-cultures containing DMSO only (** $P \leqslant 0.001)$.

a similar construction to those in the intact epididymal duct, the cultures reproduced more closely the situation in vivo than do cultures of purified epididymal principal cells, in which the architecture of the epithelium is lost unless a complex artificial basal lamina is provided (Moore et al., 1992). Studies of epididymal cell culture in both tammar wallabies and brushtail possums (Lin et al., 2000) demonstrated that cell monolayers were not formed from isolated epididymal epithelial cells sloughed from the tubule fragments treated with collagenase. This observation indicates that factors from the peritubular cells are vital for epididymal epithelial cell layers to be propagated and maintained under culture conditions. Indeed, much knowledge of the function of the eutherian epididymis is derived from the culture of epididymal tubule fragments (Moore et al., 1986, 1992; Wong, 1988a,b; Cooper et al., 1990; Leung and Wong, 1992; Leung and Wong, 1994; Raczek et al., 1994). Similar achievements have not been obtained with isolated and purified epithelium preparations, mainly because both epithelial and peritubular cells play an integral part in the function of the epididymal tubule.

Although the cultures of wallaby epididymal epithelial monolayers prepared using the method reported in the present study were heterologous populations, the epithelial cells were completely dominated in monolayers, as indicated by the immunofluorescent localization of cytokeratins, which are recognized markers of epithelial cells
(Franke et al., 1978; Sun et al., 1979; Olson et al., 1982, 1983). As the morphology of cultured epithelial cells was reorganized markedly from columnar or cuboid to a flattened-polygonal shape, it was extremely difficult to distinguish the epithelial cell types morphologically as principal, apical or basal cells, or intraepithelial leucocytes, which have been recognized in the marsupial epididymis in vivo (Orsi et al., 1981; Jones et al., 1984). However, ultrastructural observations confirmed that after 12 days in culture, the caput epididymal cells within the monolayers retained many structural features characteristic of epithelial cells in the intact epididymis. These features included very slender and branched stereocilia and microvilli located on the apical surface of the cells, a well-developed Golgi apparatus and rough endocytoplasmic reticulum network, abundant mitochondria, numerous secretory and pinocytosis vesicles, and desmosome junctions attaching neighbouring cells to form the monolayers. The features displayed were not only consistent with the ultrastructure of the intact epididymis in tammar wallabies (Jones, et al., 1984), but also with those reported in eutherian epididymal epithelial cells cultured for 3-15 days (rats: Olson et al., 1982, 1983; bulls: Joshi, 1985; hamsters: Moore and Hartman, 1986; Moore et al., 1986; humans: Cooper et al., 1989, 1990; Moore et al., 1992).

The functional integrity of the cultured epididymal epithelial cells in monolayers was indicated by the co-culture 
of 7-day-old epididymal cell monolayers with immature spermatozoa from the proximal caput epididymidis. In the present study, after $24 \mathrm{~h}$ in co-culture with epididymal cell monolayers, a proportion of spermatozoa exhibited morphological changes from the immature $\mathrm{T}$ shape to the mature streamlined shape accompanied by the development of motility. These changes indicate that some wallaby spermatozoa underwent maturational changes in vitro that are normally only manifested in vivo. The proportions of changed spermatozoa in the epididymal cell cultures were significantly higher than those in the small intestine cell cultures, indicating that the factors secreted by cultured epididymal cells ultimately affect sperm head orientation and development of motility.

Previous studies showed that whereas epididymal cells from different regions of the possum epididymis had different histological features after 7 days in culture, all had a capacity to promote sperm morphological maturation and motility development (Lin et al., 2000). Moore et al. (1992) reported that, in men, the co-culture of caput epididymal spermatozoa with cauda epididymal epithelium also promoted sperm progressive motility and sperm-zona binding capacity. These results indicate that both possum and human spermatozoa are not critically dependent on specific epididymal regions for successful maturation. Thus, only the caput epididymal cells of tammar wallabies were used to promote in vitro sperm maturation in the present study, although epithelial monolayers of the corpus and cauda epididymides were established successfully.

The presence of actin in eutherian and marsupial spermatozoa has been demonstrated in several species, including cattle, pigs, rats, mice, guinea-pigs, hamsters, moles, humans, rabbits, fat tailed dunnarts, opossums and tammar wallabies (Flaherty et al., 1986; Halenda et al., 1987; Olson and Winfrey, 1991; Castellani-Ceresa et al., 1992; MorenoFierros et al., 1992; Breed et al., 1993; Paranko et al., 1994; Scarlett et al., 2001). In tammar wallabies, actin proteins are present in the acrosome and other subcellular locations of the spermatozoa, and the occurrence of actin filaments within the acrosome is associated temporally and spatially with the process of acrosome shaping during epididymal maturation (Scarlett et al., 2001). The strong correlation between the occurrence of actin filaments and the induction of sperm maturation indicates that the post-testicular maturation of marsupial spermatozoa depends on a precise succession of assembly and disassembly of actin filaments within the spermatozoon as it transits the epididymis. This suggestion is further supported by evidence obtained from the present study using the inhibitors of actin polymerization, latrunculin A and B (Groweiss et al., 1983; Spector et al., 1989).

Both latrunculins are toxins purified from the Red Sea sponge Latrunculia magnifica and are able to interrupt the organization of actin filaments and induce striking reversible changes in the morphology of mammalian cells in culture (Groweiss et al., 1983; Spector et al., 1989). Latrunculin A affects the polymerization of pure actin in vitro in a manner consistent with the formation of a $1: 1$ molar complex between latrunculin A and G-actin (Couè et al., 1987), and is a potent inhibitor of the microfilamentmediated processes of fertilization and early development in sea urchins and mice (Schatten et al., 1986). In the present study, the immature spermatozoa were treated with actin inhibitors before and during co-culture with the epididymal cells. Both latrunculin A and B inhibited the differentiation of immature wallaby spermatozoa from a T-shaped to streamlined shape and the induction of sperm motility. As the inhibition of actin polymerization disrupts the sperm maturation, these findings indicate that actin filaments play a significant role in marsupial sperm transformation in the epididymis. However, the latrunculin inhibitors may also have an effect on epididymal cell function during co-culture, producing an indirect effect on the maturation of wallaby spermatozoa in the co-culture system. More studies are needed to elucidate the possible direct and indirect effects of actin inhibitors on wallaby sperm maturation.

The authors are grateful to Xiyi Zhang, Jenny Martin and Amanda Harman for their excellent technical support, and David Key and John Rodger for their helpful comments on the manuscript. This work was supported by grants from the Research Management Committee of the University of Newcastle and the Cooperate Research Centre Program of the Australian Government.

\section{References}

Bedford JM (1991) The coevolution of mammalian gametes. In Comparative Overview of Mammalian Fertilization pp 3-35 Eds BS Dunbar and MG O'Rand. Plenum Press, New York

Breed WG, Leigh CM and Washington JM (1993) Filamentous actin in and around spermatids of the marsupial, Sminthopsis crassicaudata. Journal of Computer-Assisted Microscopy 5 93-96

Byers SW, Citi S, Anderson JM and Hoxter B (1992) Polarized functions and permeability properties of rat epididymal epithelial cells in vitro. Journal of Reproduction and Fertility 95 385-396

Carballada R and Saling PM (1997) Regulation of mouse epididymal epithelium in vitro by androgens, temperature and fibroblasts Journal of Reproduction and Fertility 110 171-181

Castellani-Ceresa L, Brivio MF and Radaelli G (1992) F-actin in acrosome reacted boar spermatozoa Molecular Reproduction and Development 33 99-107

Couè M, Brenner SL, Spector I and Korn ED (1987) Inhibition of actin polymerization by latrunculin A Federation of European Biochemical Societies Letters 213 316-318

Cooper TG, Yeung $\mathbf{C H}$ and Meyer R (1989) Immature rat epididymal epithelial cells grown in static primary monolayer culture on permeable supports. I. Vectorial secretion Cell and Tissue Research 256 567-572

Cooper TG, Yeung CH, Meyer R and Schulze H (1990) Maintenance of human epididymal epithelial cell function in monolayer culture Journal of Reproduction and Fertility 90 81-91

Cummins JM (1976) Epididymis maturation of spermatozoa in marsupial Trichosurus vulpecula, change in motility and gross morphology Australian Journal of Zoology 24 499-511

Flaherty SP, Winfrey VP and Olson GE (1986) Localisation of actin in mammalian spermatozoa: a comparison of eight species Anatomical Record 216 504-515

Franke WW, Schmid E, Osborn M and Weber K (1978) Different intermediate-sized filaments distinguished by immunofluorescence microscopy Proceedings National Academy of Sciences USA 75 5034-5038 
Groweiss A, Shmueli U and Kashman Y (1983) Marine toxins of Latrunculia magnifica. Journal of Organic Chemistry 48 3512-3516

Halenda RM, Primakoff P and Myles DG (1987) Actin filaments, localised to the region of the developing acrosome during early stages, are lost during later stages of guinea pig spermiogenesis Biology of Reproduction 36 491-499

Harding HR, Crrick FN and Shorey CD (1976) Spermiogenesis in the brushtailed possum, Trichosurus vulpecula (Marsupialia) - the development of the acrosome Cell and Tissue Research 171 75-90

Harding HR, Carrick FN and Shorey CD (1979) Special features of sperm structure and function in marsupials. In The Spermatozoon: Maturation, Motility, Surface Properties and Comparative Aspects pp 289-303 Eds DW Fawcett and JM Bedford. Urban and Schwarzenberg, Baltimore, Munich

Harding HR, Carrick FN and Shorey CD (1983) Acrosome development during spermiogenesis and epididymal sperm maturation in Australian marsupials. In The Sperm Cell pp 411-444 Ed. J André. Martinus Nijhoff Publishers, The Hague

Harding HR, Carrick FN and Shorey CD (1984) Sperm ultrastructure and development in the honey possum, Tarsipes rostratus. In Possums and Gliders pp 451-456 Eds AP Smith and ID Hume. Australian Mammal Society, Sydney

Jones RC and Clulow J (1994) Interactions of sperm and the reproductive ducts of the male tammar wallaby, Macropus eugenii (Macropodidae: Marsupialia) Reproduction, Fertility and Development 6 437-444

Jones RC and Murdoch RN (1996) Regulation of the motility and metabolism of spermatozoa for storage in the epididymis of eutherian and marsupial mammals Reproduction, Fertility and Development 8 553-568

Jones RC, Hinds LA and Tyndale-Biscoe CH (1984) Ultrastructure of the epididymis of the tammar Macropus eugenii, and its relationship to sperm maturation Cell and Tissue Research 237 525-535

Joshi MS (1985) Isolation and cell culture of the epithelial cells of cauda epididymidis of the bull Biology of Reproduction 33 187-200

Leung AYH and Wong PYD (1992) Studies of transepithelial $\mathrm{Cl}^{-}$transport in cultured cauda epididymal cells of rats by the short-circuit current method Journal of Physiology 457 391-406

Leung AYH and Wong PYD (1994) Biphasic short-circuit current response to noradrenaline mediated by $\mathrm{Ca}^{2+}$ and cAMP in cultured rat epididymal epithelium European Journal of Physiology 426 369-401

Lin M and Rodger JC (1999) Acrosome formation during sperm transit through the epididymis in the tammar wallaby (Macropus eugenii) and the brushtail possum (Trichosurus vulpecula). Journal of Anatomy 194 223-232

Lin M, Harman A and Rodger JC (1997) Spermiogenesis and spermiation in a marsupial, the tammar wallaby (Macropus eugenii). Journal of Anatomy 190 377-395

Lin M, Zhang X, Murdoch R and Aitken RJ (2000) In vitro culture of brushtail possum (Trichosurus vulpecula). epididymal epithelium and induction of epididymal sperm maturation in co-culture Journal of Reproduction and Fertility 119 1-14

Liu DY, Martic M, Clarke JN, Dunlop ME and Baker HWG (1999) An important role of actin polymerisation in the human zona pellucidainduced acrosome reaction Molecular Human Reproduction 5 941-949

Mate KE and Rodger JC (1996) Capacitation and the acrosome reaction in marsupial spermatozoa Reproduction, Fertility and Development $\mathbf{8}$ 595-603

Moore HDM and Akhondi MD (1996) In vitro maturation of mammalian spermatozoa Reviews of Reproduction 154-60

Moore HDM and Hartman TD (1986) In vitro development of fertilizing ability of hamster epididymal spermatozoa after co-culture with epithelium from the proximal cauda epididymis Journal of Reproduction and Fertility 78 347-582

Moore HDM, Hartman TD and Smith CA (1986) In vitro culture of hamster epididymal epithelium and induction of sperm motility Journal of Reproduction and Fertility 78 327-336

Moore HDM, Curry MR, Penfold LM and Pryor JP (1992) The culture of human epididymal epithelium and in vitro maturation of epididymal spermatozoa Fertility and Sterility $\mathbf{5 8}$ 776-783
Moreno-fierros L, Hernandez EO, Salgado ZO and Mujica A (1992) F-actin in guinea pig spermatozoa: its role in calmodulin translocation during acrosome reaction Molecular Reproduction and Development 33 172-181

Olson GE and Winfrey VP (1991) Changes in actin distribution during sperm development in the opossum, Monodelphis domestica. Anatomical Record 230 209-217

Olson GE, Jonas-Davies J, Hoffman LH and Orgebin-Crist M (1982) Structural characterization of isolated rat epididymal epithelial cells Gamete Research 6 161-178

Olson GE, Jonas-Davies J, Hoffman LH and Orgebin-Crist M (1983) Structural features of cultured epithelial cells from the adult rat epididymis Journal of Andrology 4 347-360

Orsi AM, Ferreira AL, de Mello VR and Oliveira MO (1981) Regional histology of the epididymis in the South American opossum. Light microscope study Anatomischer Anzeiger 150 521-528

Paranko J, Yagi A and Kuusisto M (1994) Immunocytochemical detection of actin and $53 \mathrm{kDa}$ polypeptide in the epididymal spermatozoa of rat and mouse Anatomical Record 240 516-527

Raczek S, Yeung CH, Hasilik A, Robenek H, Hertle L, Schulze H and Cooper TG (1994) Epithelial monolayers from human epididymal and efferent duct tubules; testosterone metabolism and effects of culture conditions on cell height and confluence Epithelial Cell Biology 3 126-136

Reynolds ES (1963) The use of lead citrate at high $\mathrm{pH}$ as an electron-opaque stain in electron microscopy Journal of Cell Biology 17 208-212

Rodger JC (1997) Likely targets for immunocontraception in marsupials Reproduction, Fertility and Development 9 131-136

Scarlett CJ, Lin M and Aitken RJ (2001) Actin polymerisation during morphogenesis of the acrosome as spermatozoa undergo epididymal maturation in the tammar wallaby (Macropus eugenii). Journal of Anatomy 198 93-101

Schatten G, Schatten H, Spector I, Cline C, Paweletz N, Simerly C and Petzelt C (1986) Latrunculin inhibits the microfilament-mediated processes during fertilization, cleavage and early development in sea urchins and mice Experimental Cell Research 166 192-208

Setchell BP (1970) Fluid secretion by the testis of Australian marsupial, Macropus eugenii. Comparative Biochemistry and Physiology 36 411-414

Setiadi D, Lin M and Rodger JC (1997) Posttesticular development of spermatozoa of the tammar wallaby (Macropus eugenii). Journal of Anatomy $190275-288$

Spector I, Shochet NR, Blasberger D and Kashaman Y (1989) Latrunculins novel marine macrolides that disrupt microfilament organization and affect cell growth. I. Comparison with cytochalasin D Cell Motility and the Cytoskeleton 13 127-144

Sun EL, Shih C and Green H (1979) Keratin cytoskeletons in epithelial cells of internal organs Proceedings National Academy of Sciences USA 76 2813-2817

Temple-Smith PD (1994) Comparative structure and function of marsupial spermatozoa Reproduction, Fertility and Development 6 421-435

Temple-Smith PD and Bedford JM (1976) The features of sperm maturation in the epididymis of a marsupial, the brushtailed possum Trichosurus vulpecula. American Journal of Anatomy 147 471-500

Wong PYD (1988a) Mechanism of adrenergic stimulation of anion secretion in cultured rat epididymal epithelium American Journal of Physiology 254 121-133

Wong PYD (1988b) Inhibition by chloride channel blockers of anion secretion in cultured epididymal epithelium and intact epididymis of rats Journal of Pharmacology 94 155-163

Yeung CH, Cooper TG and Meyer R (1989) Immature rat epididymal epithelial cells grown in static primary monolayer culture on permeable supports. II. Histochemistry and ultrastructure Cell and Tissue Research $256573-580$

Received 12 December 2001.

First decision 23 January 2002.

Revised manuscript received 11 March 2002.

Accepted 21 March 2002. 